\title{
BLOCKCHAIN AND TECHNOLOGIES MATCHING WITH THE CASE of Study of Vegetables Production
}

\author{
Alessandro Massaro, Vincenzo Maritati, Nicola Savino, Angelo Galiano, and Ugo Picciotti
}

\begin{abstract}
The proposed work describes a new approach based on supply chain traceability by blockchain (BC). The basic BC network has been designed and applied for vegetables process monitoring and tracing. The paper proposes some results of an industry research project by describing the whole scenario, the architectures implementing $\mathrm{BC}$, the sequence diagram principle, and the prototype network embedding blocks and transactions. The discussion is also addressed on the possibility to combine different technique such as artificial intelligence, and image processing to improve pre-cut vegetable quality. The paper proposed preliminary results proves that the adopted technologies and the methodologies found in the literature are suitable for the sanitation process certification and for quality traceability. The mentioned approaches are useful to apply the suggested frameworks for other supply chains.
\end{abstract}

Keywords-Blockchain, Production Process monitoring, Production Quality Improvement, Supply Chain.

\section{INTRODUCTION: APPLICATION FIELD AND RELATED WORKS}

TNDUSTRY 4.0 facilities and artificial intelligence play

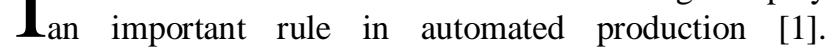
Production processes can be digitally traced and certified by means of blockchain technology. By considering a specific case of study of vegetable production, the blockchain could certify important and delicate processes such as sanitization and pre-treatment. The sanitization of pre-cut vegetables requires a particular study about the substances to be used. In literature various substances have been analyzed for the treatment such as ozone, electrolyzed water, and hydrogen peroxide $\left(\mathrm{H}_{2} \mathrm{O}_{2}\right)$ [2] The procedure of combining multiple substances is therefore a possibility already addressed in the literature where the combination of ozone with hydrogen peroxide

\footnotetext{
All authors are with Dyrecta Lab srl,IT Research Laboratory, via Vescovo Simplicio,45, 70014 Conversano (BA), Italy (corresponding author, phone: +39 0804958477; fax: +39 0804099028; e-mail: alessandro.massaro@dyrecta.com)
}

Copyright $($ C) Authors
$\left(\mathrm{H}_{2} \mathrm{O}_{2} / \mathrm{O}_{3}\right)$ was studied for the elimination of THMs (trihalomethanes), believed to be the cause of tumors in animals [3]. The sanitization and processing studies must therefore make a significant contribution to the shelf life of the product [4], and must be oriented towards the optimization of the parameters. Of particular importance is in fact the condition in which the vegetables arrive at this sanitizing treatment process. In fact, considering the entire supply chain, the entire production process could be assessed including the pre-treatment operations resulting from the vegetable harvesting phase. In this context, several studies have been carried out concerning

the possibility of eliminating fungi and phytophages in the pre- and post-harvest phase (pre-harvest post-harvest application) [6]-[11]. The traceability of the processes of the entire supply chain therefore plays an important role for product/process optimization. In this direction, the blockchain (BC) could be implemented as a tool capable of digitizing the information of the production chain. By definition, the blockchain (BC) [12]-[21] is a shared and unchangeable chain of data blocks, defined as a digital register whose entries are grouped into "pages" (called blocks), linked in chronological order, and whose integrity is guaranteed by the use of primitives cryptographic. Although its size is destined to grow over time, it is immutable, and its content is no longer editable or eliminable, unless it invalidates the entire structure. The blocks structure [12]-[14] in specific protocols taking into account data transactions such as request, verification and validation. The $\mathrm{BC}$ structure becomes more complex for information updating in the entire supply chain of the production of pre-cut vegetables. The data packaging methods become more complex considering that the blocks whose data must be encrypted so that they are not "attacked" from the outside (encryption process). BC has been applied in the literature for the traceability of products, as demonstrated in [15], where there has been a positive response about the traceability of wine considering the entire product supply chain. Also, safe traceability and logistics are important to map by $\mathrm{BC}$ [17]-[21]. A scientific upgrade of the BC can be achieved by "interconnecting" it with artificial intelligence (AI) 
IT in Industry, vol. 8, no.2, 2020

engines [22]-[27]. In [28]-[30] there are applications of blockchain in the food sector thus confirming that the issue is of scientific interest.

Based on these premises, the work hereby presented is structured as follows:

(i)Description the of the whole scenario within has been developed the paper by indicating the main specifications;

(ii) Design of the blockchain infrastructure and the sequence logic of the data transactions;

(iii) Testing of the first created nodes of the blockchain by means of suitable tools;

(iv) Discussion about technologies found in literature testing image processing technique able to detect vegetables defect;

(v) Illustration of the experimental field

(vi) Discussion and conclusions about possible improvements adopting AI and other methodologies found in the state of the art.

\section{PRELIMINARY PROJECT SCENARIO}

Following the state of the art has been formulated the architecture of Fig 1 representing the scenario of the project research. The architecture represents a digital information system linked to the optimization and quality production processes of pre-cut vegetables. In particular, all supply chain processes will be optimized by planning experimental development activities. The design of effective production systems is optimized by $\mathrm{BC}$ and artificial intelligence, as quality certification tool and decision support system (DSS) for the optimization of production processes, respectively. The research project will concern the development of the following project modules:

- Sanitization/Processing Module. The module will concern the innovation of the sanitization and processing of pre-cut vegetables ready for consumption. This module includes procedures and protocols for vegetables treatment following the integration and the combination of technologies/ methodologies concerning different liquid and gaseous substances. The module therefore includes the study of:

i) basic research related to the interaction of different liquid and/or gaseous substances used for the treatment of vegetables;

ii) the study of treatment adopting operating conditions (temperature, pressure, etc.) useful for the design of a pilot treatment machine;

Copyright $\odot$ Authors
Published online 07-Aug-2020

iii) the design and development of experimental setup useful for the scientific validation of the acquired methods, focusing the attention on the sanitization in pretreatment processes.

- Module of pre-treatment and post-harvest process of vegetables. This module includes the studies of methods adopting inert substances and surfactants, by distinguishing the procedures to be applied for organic and integrated cultivation. The goal will therefore be to avoid contamination by fungi and phytophagous. Of particular interest will also be the study of substances that act directly on the characteristics of the water.

- Blockchain (BC) module. The production phases will be "recorded" in the blocks of the blockchain which will guarantee the traceability and effectiveness of the pretreatments and treatments of the analyzed methodologies. The block infrastructure will contain information of the whole supply chain.

- Artificial Intelligence (AI) Module. Artificial intelligence algorithms can be used to optimize all production phases [31]-[34]. The algorithms constitute the DSS for product optimization. The AI engine will process the data contained in the individual blocks of the supply chain and will also carry out time forecasting analysis in order to optimize the product quality by identifying possible critical issues in the production process (processing inefficiencies, delays in transport, risk of persistent contamination, etc.). In Fig. 1 is indicated a general functional scheme of the research project architecture.

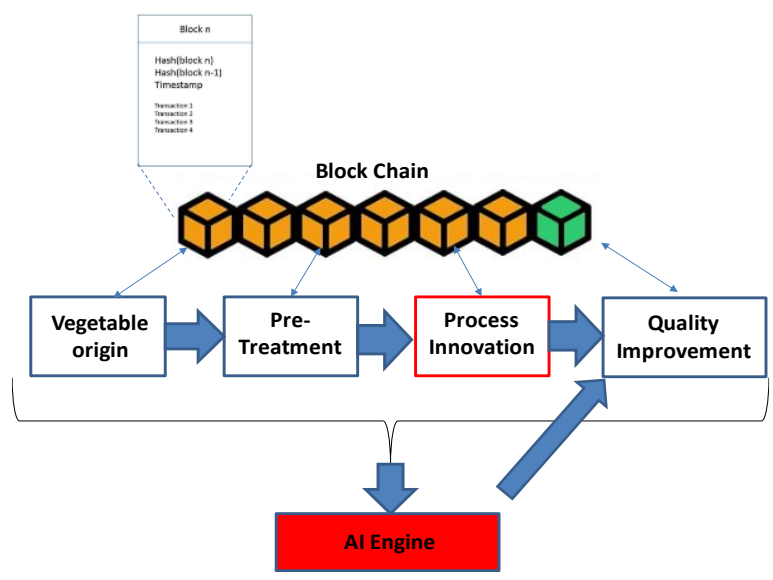

Fig. 1 Blockchain and vegetable production supply chain traceability by blockchain ('MESLO' project). 
IT in Industry, vol. 8, no.2, 2020

The attention of this work is addressed mainly on the BC module tracing the following stages:

- information about vegetable origin (field geolocalization, climate, product management, etc.);

- data of the applied pre-treatment (applied methodologies, quality check, etc.);

- process innovation (quality improvements due to the production process innovation);

- quality information about process optimization improving quality.

In particular The AI algorithms will be applied in order to improve the pre-cut vegetables quality supporting the optimization of the sanitation process: the AI algorithm are able to process multiple attributes finding the sanitation features and

classifying the best production processes to apply. On the other side, the BC will certify the best processed product.

\section{BLOCKCHAIN ARCHITECTURE AND IMPLEMENTATION}

The BC network illustrated in Fig. 1 has "exploded" in the architecture of Fig. 2 indicating how all the nodes of the network (node1, node2,...) have their own local copy of the blockchain, which is composed of a sequence of blocks containing all the information relating to the stored transactions (transaction 1 , transaction $2, \ldots$ ).

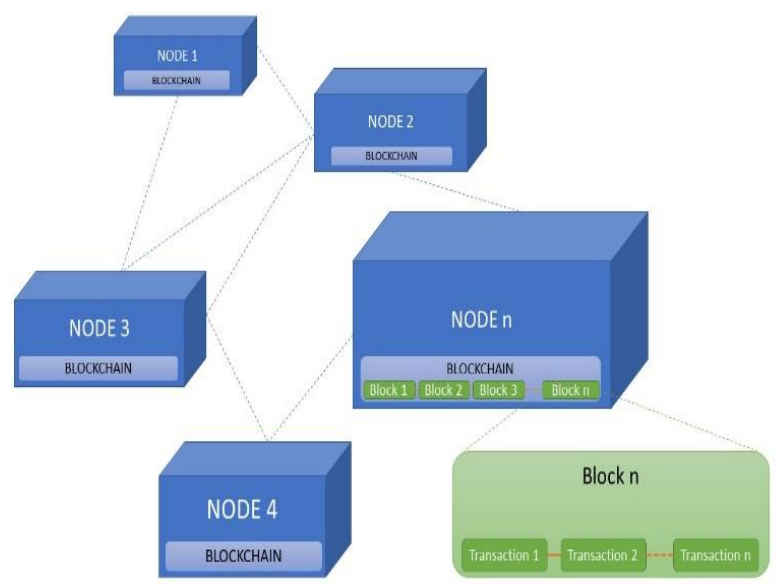

Fig. 2 Block diagram of node interconnection and data packaging.

The BC network illustrated in Fig. 1 is stored in each node of the network, so that there are multiple distributed

Copyright () Authors
Published online 07-Aug-2020

copies of the same ledger, containing all the transactions approved by the system. The blockchain architecture is integrated into the Enterprise Resource Planning (ERP) environment using secure data transfer channels, such as HTTPS, allowing high integration of all the players in the system, as illustrated in Fig. 3. By this way, the blockchain network can be easily interfaced with IoT (Internet of Things) devices and mobile applications and can allow the use of artificial intelligence algorithms that use the data stored in transactions to make predictions and classifications, useful to increase the efficiency and the quality of the company's production.

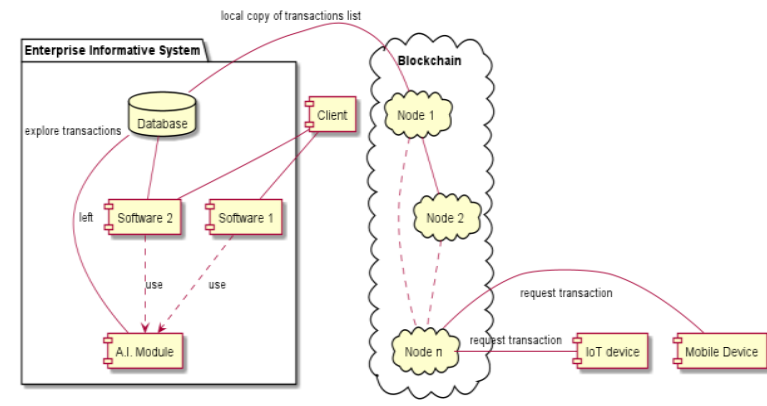

Fig. 3 System architecture integrating IoT devices, Mobile APP, ERP, and AI with the blockchain network.

Below is reported an example of transaction formulation by representing some generic declared field used for the testing of the basic implemented blockchain network (JSON dictionary):

transaction $=\{$

'uin': integer

(unique identification number of the actor involved in the event to be stored in a transaction)

'uin_device': integer

(unique identification number of the device generating the transaction)

'data' : json data

(data generated in the phase stored in the transaction) 'timestamp': integer

\}

The single block has been implemented by the following structure (JSON dictionary):

$$
\begin{aligned}
& \text { block }=\{ \\
& \text { 'index' : integer, } \\
& \text { 'timestamp' : integer, }
\end{aligned}
$$




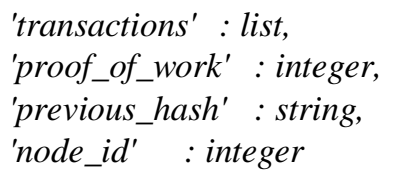

A block is therefore characterized by a numerical index which reports its position within the chain of blocks, the timestamp relating to the moment in which it was created, the transactions, the "proof" of Proof of Work (PoW), the block hash that precedes the current and the unique identifier of the node that creates the block. PoW protocol is an inexpensive measure to discourage denial of service attacks and other abuse of service. A key feature of these schemes is their asymmetry: the job must be moderately complex but feasible on the requesting side and easy for the service provider to control. With block information it is possible to check:

- the correct sequence of information blocks by timestamp information and index number;

- the authenticity and immutability of the information contained, thanks to the hashing of the previous block present in each block since by corrupting an intermediate block, all subsequent blocks would have an incorrect hash;

- stability in the construction of the blockchain through PoW.

Other consensus algorithms can be used, such as PoS (Proof of Stake) or PoC (Proof of Capacity) as well as hybrid solutions; a PoW algorithm with a low difficulty has been implemented in the prototype under analysis, in order to maintain a high degree of reliability and, at the same time, not be excessively time and power consuming. The implementation of the PoW algorithm provides 128bit hashing of the concatenation of:

- the last PoW;

- the current PoW;

- the last block hash;

This hashing is performed until the last 8 characters of the obtained string are all equal to zero.

It is also possible to introduce further information within each block simply by expanding its dictionary to allow the insertion of further key / value pairs, such as the GPS position where the block is created.
In the case of application in a public environment, without the use of a Virtual Private Network (VPN) or Local Area Network (LAN), it is possible to encrypt the individual blocks using public/private keys, in order to guarantee the confidentiality of the data involved, as well as the individual transactions contained in each block. The implemented network prototype is based on a class called "Blockchain" which contains all the methods and attributes necessary for the correct implementation of the blockchain. From this class an object is instantiated which will be used at the application level by the web server and which allows intercommunication between the blockchain nodes and the actors (information systems, IoT and mobile devices) involved; the instantiated object represents a node in the network of nodes that make up the system. For the implementation of the prototype, Python 3.7 and the Flask microframework, based on Web Server Gateway Interface (WSGI), has been used.

In Fig. 4 is illustrated the UML (Unified Modelling Language) design of the sequence diagram implemented in the prototype Blockchain network, where Actor $\mathrm{X}$ indicates the element of the supply chain of Fig. 1 inserting data or information.

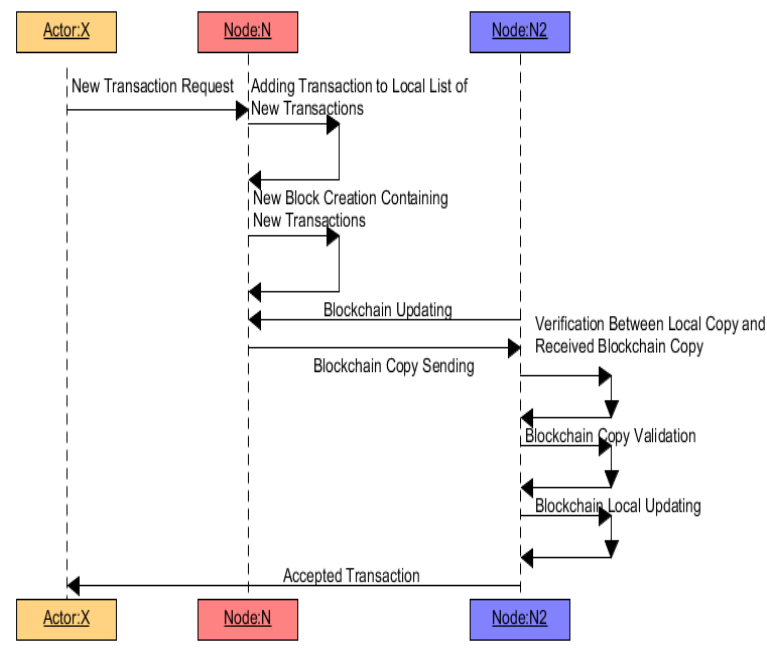

Fig. 4 Sequence diagram: system architecture integrating IoT devices, Mobile APP and ERP with blockchain network.

In Fig. 5 is illustrated a screenshot of the Postman interface used for the testing of the prototype blockchain platform. 
IT in Industry, vol. 8, no.2, 2020

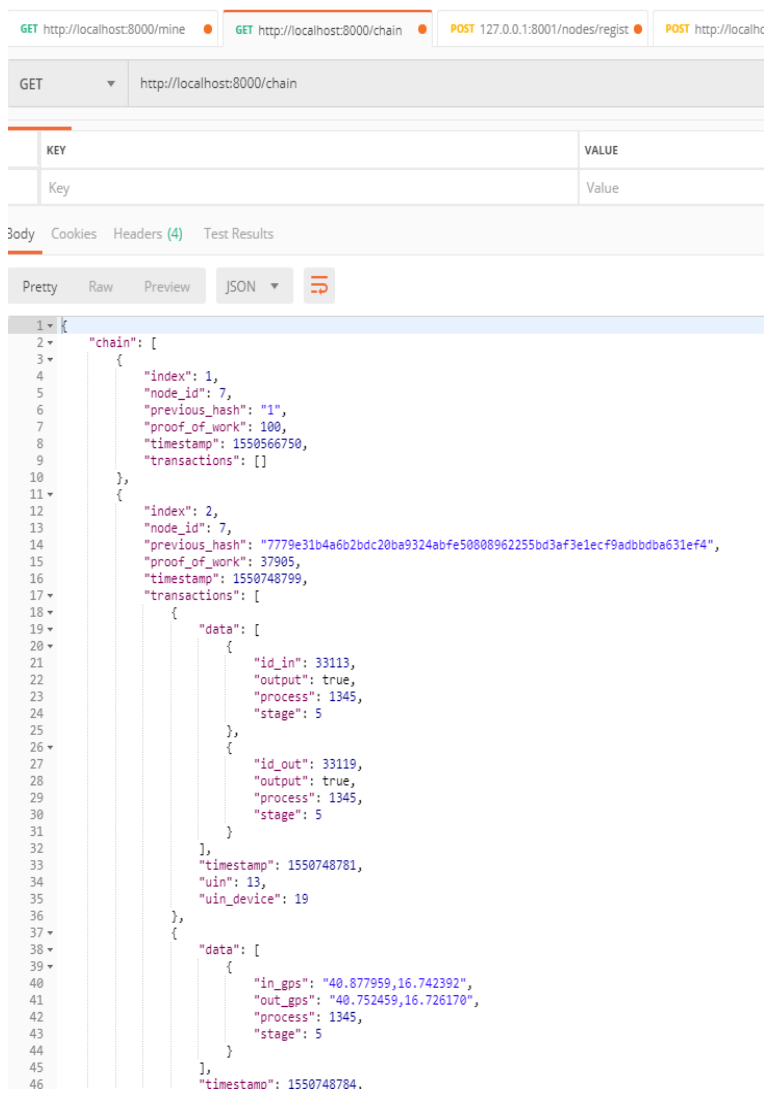

Fig. 5 Postman interface testing blockchain prototype platform.

The following diagram shows the class diagram relating to the Blockchain class:

\begin{tabular}{|c|}
\hline Blockchain \\
\hline $\begin{array}{l}\text {-new_transactions: list } \\
\text {-chain: list } \\
\text {-nodes: set } \\
\text { «property»+get_last_block: string }\end{array}$ \\
\hline $\begin{array}{l}\text { +_init__ } \\
\text { +add_node(address: string) } \\
\text { +chain_validation(chain: list): boolean } \\
\text { +consensus(): boolean } \\
\text { +add_block(proof: string, previous_hash: string): string } \\
\text { +add_transaction(uin: integer, uin_device: integer, data: string, timestamp: integer): string } \\
\text { +get_last_block(): string } \\
\text { +get_last_blocks(from_index: integer =0): list } \\
\text { +hash(string): string } \\
\text { +proof_of_work(string): integer } \\
\text { +proof_of work validation(actual proof, last proof, last hash): boolean }\end{array}$ \\
\hline
\end{tabular}

Fig. 6 Blockchain class diagram.

\section{DISCUSSION AND CONCLUSIONS}

The work proposes a case of study implementing Blockchain network to certify and trace the production activities of the supply chain. A particular attention is focused on the concept of the blockchain network creation
Published online 07-Aug-2020

by discussing the basic procedures to implement structured blocks containing transaction information. The paper introduces elements useful to practically develop a blockchain network improving production quality. The results are developed within the framework of a research project regarding the improvement and the traceability of vegetable supply chain. The frameworks discussed in the paper can be implemented in other industrial scenarios involving Industry 4.0 facilities and artificial intelligence improving supply chain [36],[37]. In food factory the blockchain could guarantee the product quality by integrating traceability information and quality test results. Concerning food quality processes $\mathrm{BC}$ can be also a tool suitable to map product defects within a defined tolerance: product defects detection can be supported by image vision techniques [33],[36],[38]. In Fig. 7 is illustrated an example of image segmentation extracting defect surfaces of a sample used for the experimentation. The image vision approaches could be applied on the detection of vegetables defects adding information in $\mathrm{BC}$ blocks for example about the defect percentage detected.
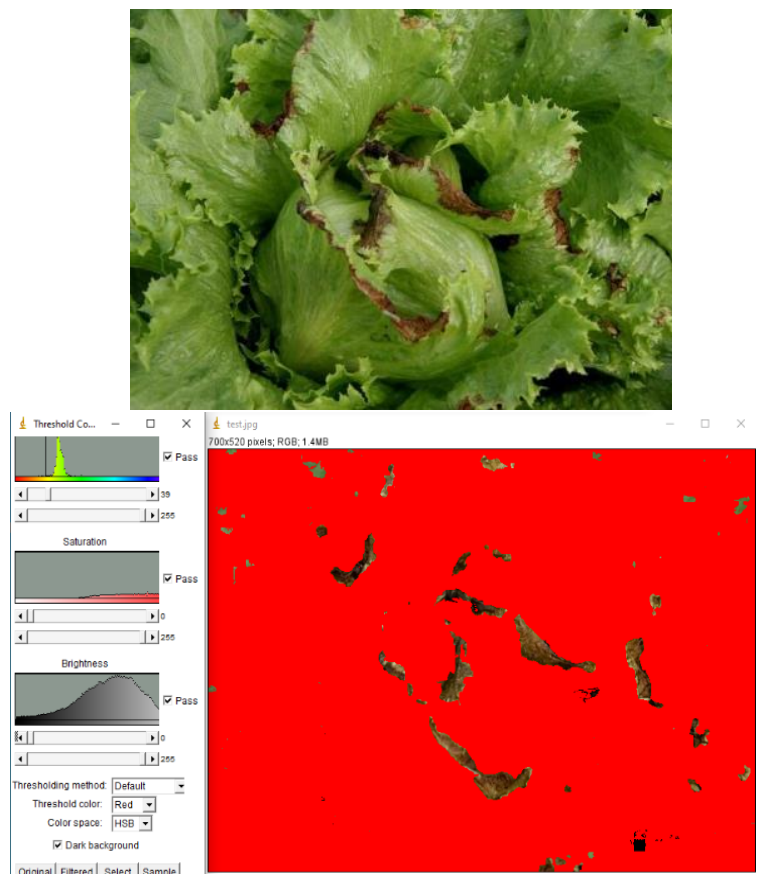

Fig. 7 Vegetable burn defect and image processing.

Artificial Intelligence algorithms could support defect classification and in general production efficiency. In this direction neural networks such as Long Short Term Memory (LSTM) [39] and Artificial Neural Networks (ANNs) [40] could also be applied for: 
IT in Industry, vol. 8, no.2, 2020

- processing production inefficiencies: the LSTM/ANNs networks could predict sanitation inefficiencies by processing and crossing data of the experimental test of cultivation (in Fig. 7 is shown the experimental field used to acquire and to collect data for the preprocessing of vegetables); the $\mathrm{BC}$ will include data and information about sanitation test by adopting different no-chemical pre-treatment solutions;

- delays in transport: the algorithms predict production according to metrological sales prediction [41],[42];

- risk of persistent contamination: the neural network could predict the contamination evolution by indicating the risk using different approaches for sanitation;

- field condition prediction: precision agriculture and data mining [43],[44] could facilitate the data processing by analyzing other factors that could influence product sanitation such as hydric stress, temperature, humidity and evapotranspiration [45].

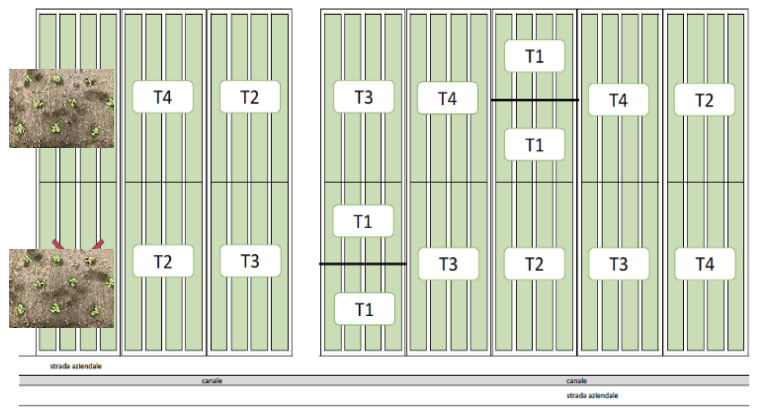

Fig. 8 Testing field layout: the total plants are 16800 grouped into sectors $\mathrm{T}$ with the same plant typology and treatment (T1, $\mathrm{T} 2$, T3 and T4). The parameters to be measured are: number of healthy plants, number of plants infected with Fusarium spp., number of plants infected with Sclerotinia spp. and number of plants infected with Botrytis Cinerea, with reliefs conducted in pre-harvest and post-harvest. Inset: "Pan di Zucchero" plants.

The production process traceability by BC could activate automatic smart contracts thus accelerating marketing and commercial processes. The BC implementation concerning all the supply chain phases of the industry project is under investigation. The AI algorithms will be applied in order to address the research about sanitation in the best way improving pre-cut vegetables quality. The $\mathrm{BC}$ will certify the best processed product.

\section{ACKNOWLEDGEMENTS}

The work has been developed in the framework of the project: "Nuove MEtodologie per la riduzione di prodotti
Published online 07-Aug-2020

chimici nella Sanificazione/Lavorazione degli Ortaggi pre-tagliati pronti al consumo 'MESLO' [New methodologies for the reduction of chemicals in the sanitation / processing of pre-cut vegetables ready for consumption "MESLO"].

\section{REFERENCES}

[1] A. Massaro, N. Contuzzi and A. Galiano, "Intelligent Processes in Automated Production Involving Industry 4.0 Technologies and Artificial Intelligence," book chapter: Advanced Robotics and Intelligent Automation in Manufacturing, IGI GLOBAL, ISSN: 2327-0411, DOI: 10.4018/978-1-7998-1382-8.ch004, ch.4, pp. $97-$ $122,2020$.

[2] M. A. Alsheyab and A. H. Muñoz, "Reducing the formation of trihalomethanes (THMs) by ozone combined with hydrogen peroxide $\left(\mathrm{H}_{2} \mathrm{O}_{2} / \mathrm{O}_{3}\right)$," Desalination, Vol. 194, 2006, No. 1-3, pp. $121-126$.

[3] A. Gopal, J. Coventry, J. Wan, H. Roginski, S. Ajlouni, "Alternative disinfection techniques to extend the shelf life of minimally processed iceberg lettuce," Food Microbiology, Vol. 27, No. 2, 2010, pp. 210-219.

[4] M. A. Khawarizmi and Phebe, Ding, "Ozone Application in Fresh Fruits and Vegetables," Pertanika Journal of Scholarly Research Reviews, Vol. 4, No. 2, 2018, pp. 29-35.

[5] A. Ippolito, L. Schena, I. Pentimone and F. Nigro, "Control of postharvest rots of sweet cherries by pre- and postharvest applications of Aureobasidium pullulans in combination with calcium chloride or sodium bicarbonate," Postharvest Biology and Technology, Vol. 36, No. 3, 2005, pp. 245-252.

[6] L. Pinto, A. Ippolito and F. Baruzzi, "Control of spoiler Pseudomonas spp. on fresh cut vegetables by neutral electrolyzed water," Food Microbiology, Vol. 50, 2015, pp. 102-108.

[7] G. Romanazzi, F. Nigro andA. Ippolito, "Effetto di trattamenti pre- e post- raccolta con chitosano sui marciumi della fragola in conservazione," Frutocoltura, Vol. 62, No.5, 2000, pp. 71-75.

[8] A. El-Ghaouth, J. L. Smilanick, G. E. Brown, M. Wisniewski and C. L. Wilson, "Application of Candida saitoana and Glycolchitosan for the control of postharvest diseases of apple and citrus fruit under semi-commercial conditions," Plant Disease, Vol. 84, No. 3, pp. 244-248.

[9] F. Nigro, L. Schena, A. Ligorio, I. Pentimone, A. Ippolito and M. G. Salerno, "Control of table grape storage rots by pre-harvest applications of salts," Postharvest Biology and Technology, Vol. 42, No. 2, 2006, pp. 142-149.

[10] G. Romanazzi, F. Nigro, A. Ippolito, D. Di Venere and M. Salerno, "Effects of pre- and postharvest chitosan treatments to ControlnStorage grey mold of table grapes," Journal of Food Science, Vol. 67, No. 5, 2002, pp. 1862-1867.

[11] P. Bertolini and D. Missere, "Metodi innovativi di gestione dei frutti nella fase post-raccolta,"Rete interregionale per la ricerca agraria, forestale, acquacoltura e pesca, Regione Emilia Romagna, 2010.

[12] Z. Zheng, S. Xie, H. Dai, X. Chen and H. Wang, "An overview of blockchain technology: architecture, consensus, and future trends," Proceeding of IEEE 6th International Congress on Big Data, 2017 ,pp. 559- 564.

[13] D. Puthal, N. Malik, S. P. Mohanty, E. Kougianos and G. Das, "Everything you wanted to know about the blockchain: its promise, components, processes, and problems," IEEE Consumer Electronics Magazine, Vol. 7, No. 4, 2018, pp. 6-14.

[14] B. Koteska, E. Karafiloski and A. Mishev, "Blockchain implementation quality challenges: a literature review," Proceedings of the SQAMIA 2017, 6thWorkshop of Software 
Quality, Analysis, Monitoring, Improvement, and Applications, Belgrade, Serbia, 11-13.9.2017.

[15] K. Biswas, V. Muthukkumarasamy and W. L. Tan, "Blockchain based wine supply chain traceability system," Future Technologies Conference (FTC) 2017, 29-30 November 2017,Vancouver, Canada, pp. 56-62.

[16] A. Lei, H. Cruickshank, Y. Cao, P. Asuquo, C. P. A. Ogah, and Z. Sun, "Blockchain-based dynamic key management for heterogeneous intelligent transportation systems," IEEE Internet Things J., Vol. 4, No. 6, 2017, pp. 1832-1843.

[17] M. Raya, P. Papadimitratos, and J. p. Hubaux, "Securing vehicular communications," IEEE Wireless Communications, Vol. 13, No. 5, 2006, pp. 8-15.

[18] P. Verhoeven, F. Sinn and T. T. Herden, "Examples from blockchain implementations in logistics and supply chain management: exploring the mindful use of a new technology," Logistics, Vol .2, No. 2, 2018.

[19] M. Dobrovnik, D. M. Herold, E. Fürst and S. Kummer, "Blockchain for and in logistics: what to adopt and where to start," Logistics, Vol. 2, No. 18, 2018.

[20] N. Hackius and M. Petersen, "Blockchain in logistics and supply chain: trick or treat?," Published in: Digitalization in Supply Chain Management and Logistics; Wolfgang Kersten, Thorsten Blecker and Christian M. Ringle (Eds.), ISBN 9783745043280, Oktober 2017, epubli.

[21] Y. Yanovich, I. Shiyanov, T. Myaldzin, I. Prokhorov, D. Korepanova and S. Vorobyov, "Blockchain-based supply chain for postage stamps," Informatics, Vol. 5, No. 42, 2018.

[22] I. Karamitsos, M. Papadaki, N. B. Al Barghuthi, "Design of the blockchain smart contract: a use case for real estate," Journal of Information Security, Vol. 9, No. 3, 2018, pp. 177-190.

[23] T. Marwala and B. Xing, "Blockchain and artificial intelligence," SSRN Electronic Journal, 2018.

[24] A. Garg and A. Garg, "Blockchain for artificial intelligence," International Journal for Research in Applied Science \& Engineering Technology (IJRASET), Vol. 5, No. 11, 2017.

[25] K. Salah, M. H. Rehman, N. Nizamuddin, and A. Al-Fuqaha, "Blockchain for AI: review and open research challenges," IEEE Access, Vol. 7, 2019, pp. 10127-10149.

[26] S. Makridakis, A. Polemitis, G. Giaglis and S. Louca, "Blockchain: the next breakthrough in the rapid progress of AI," Robot Autom. Eng. J., Vol. 2, No. 4, 2018, pp .1-12.

[27] R. Pulungan, S. Pulung Nugroho, N. El Maidah, T. B. Atmojo, P. D. Hardo and P. Pawenang, "Design of an intelligent warehouse management system," Information Systems International Conference (ISICO), 2 - 4 December 2013.

[28] R. Kamath, "Food Traceability on blockchain: Walmart's pork and mango pilots with IBM," The Journal of the British Blockchain Association, Vol. 1, No. 1, 2018, pp.47-53.

[29] D. Mao, Zhihao Hao, Fan Wang, and Haisheng Li, "Innovative blockchain-based approach for sustainable and credible environment in food trade: a case study in shandong province, China," Sustainability, Vol. 10, No. 3149, 2018, pp. 1-17.

[30] I.-C. Lin, H. Shih, J.-C. Liu, Y.-X. Jie, "Food Traceability System using Blockchain," inProceedings of 79th IASTEM International Conference, Tokyo, Japan, 6th-7 th October 2017, pp. 59-64.

[31] A. Massaro, I. Manfredonia, A. Galiano, L. Pellicani, and V. Birardi, "Sensing and Quality Monitoring Facilities Designed for Pasta Industry Including Traceability, Image Vision and Predictive Maintenance," in Proceeding of IEEE International Workshop on Metrology for Industry 4.0 and IoT, 2019, pp. 68-72, https://doi.org/10.1109/METROI4.2019.8792912.

[32] A. Massaro, N. Contuzzi, A. Galiano, I. Manfredonia, and B. Xhahysa, "A Preliminar Research Industry Project: a Case of Study defining Requirements for Knowledge Base Gain and Technological Upgrade in Industry Working in Train Parts Processing and Testing," in Proceeding of IEEE International
Workshop on Metrology for Industry 4.0 and IoT, pp. 172-176, https://doi.org/10.1109/METROI4.2019.8792850.

[33] A. Massaro, I. Manfredonia, A. Galiano, and B. Xhaysa, "Advanced Process Defect Monitoring Model and Prediction Improvement by Artificial Neural Network in Kitchen Manufacturing Industry: a Case of Study," in Proceeding of IEEE International Workshop on Metrology for Industry 4.0 and IoT, 2019, pp. 64-67,https://doi.org/10.1109/METROI4.2019.8792872 .

[34] N. Contuzzi, A. Massaro, I. Manfredonia, A. Galiano, and B. Xhahysa, "A Decision Making Process Model based on a Multilevel Control Platform Suitable for Industry 4.0," in Proceeding of IEEE International Workshop on Metrology for Industry 4.0 and IoT, 2019, pp.127-131, https://doi.org/10.1109/METROI4.2019.8792854.

[35] A. Massaro, V. Maritati, A. Galiano, V. Birardi, and L. Pellicani, "ESB Platform Integrating KNIME Data Mining Tool oriented on Industry 4.0 Based on Artificial Neural Network Predictive Maintenance," International Journal of Artificial Intelligence and Applications(IJAIA), Vol.9, No.3, May 2018, pp. 1-17, doi: 10.5121/ijaia.2018.9301.

[36] A. Massaro, and A. Galiano, A., "Re-Engineering Process in a Food Factory: An Overview of Technologies and Approaches for the Design of Pasta Production Processes,"Production \& Manufacturing Research,Vol. 8, No. 1, 2020, pp. 80-100, https://doi.org/10.1080/21693277.2020.1749180.

[37] A. Massaro, G. Dipierro, A. Saponaro, and A. Galiano, "Data Mining Applied in Food Trade Network," International Journal of Artificial Intelligence and Applications (IJAIA), Vol.11, No.2, 2020, pp. 15-34, doi: 10.5121/ijaia.2020.11202.

[38] A. Massaro, and Galiano, "Image Processing and Post-Data Mining Processing for Security in Industrial Applications: Security in Industry," IGI Global 2020, Handbook of Research on Intelligent Data Processing and Information Security Systems, Ch. 6, pp117-146, doi: 10.4018/978-1-7998-1290-6.ch006.

[39] A. Massaro, V. Maritati, D. Giannone, D. Convertini, and A. Galiano, (2019) "LSTM DSS Automatism and Dataset Optimization for Diabetes Prediction," Applied Sciences, Vol. 9, No. 17, 2019, pp. 1-22, https://doi.org/10.3390/app9173532 .

[40] A. Massaro, V. Maritati, N. Savino, A. Galiano, D. Convertini, E. De Fonte, M. Di Muro, "A Study of a Health Resources Management Platform Integrating Neural Networks and DSS Telemedicine for Homecare Assistance," Information, Vol. 9, No. 7, 2018, pp. 1-20, https://doi.org/10.3390/info9070176.

[41] A. Massaro, D. Barbuzzi, V. Vitti, A. Galiano, M. Aruci, and G. Pirlo, "Predictive Sales Analysis According to the Effect of Weather," in Proceeding of the 2nd International Conference on Recent Trends and Applications in Computer Science and Information Technology, Tirana, Albania, November 18 - 19, 2016, pp. 53-55, http://ceur-ws.org/Vol-1746/paper-09.pdf.

[42] A. Massaro, V. Vitti, A. Galiano, and A. Morelli, A., "Business Intelligence Improved by Data Mining Algorithms and Big Data Systems: an Overview of Different Tools Applied in Industrial Research," Computer Science and Information Technology, Vol. 7, No.1, 2019, pp. 1-21, doi: 10.13189/csit.2019.070101.

[43] A. Massaro, G. Meuli, N. Savino, and A. Galiano, "A Precision Agricolture DSS Based on Sensor Threshold Management for Irrigation Field," Signal \& Image Processing: An International Journal (SIPIJ), Vol. 9, 2018, pp. 39-58, doi: 10.5121/sipij.2018.9604.

[44] A. D'Accolti, S. Maggio, A. Massaro, A. Galiano, V. Birardi, L. Pellicani, "Assessment of Data Fusion Oriented on Data Mining Approaches to Enhance Precision Agriculture Practices aimed at Increase of Durum Wheat (Triticum turgidum L. var. durum) Yield," Journal of Food, Nutrition and Agriculture, Vol. 1, No. 1, 2018, pp. 47-54, http://dx.doi.org/10.21839/jfna.2018.v1i1.229.

[45] E. Obada, E. A. Alamou, A. Chabi, J. Zandagba, A. Afouda, "Trends and Changes in Recent and Future Penman-Monteith 
IT in Industry, vol. 8, no.2, 2020

Potential Evapotranspiration in Benin (West Africa)," Hydrology,
Vol.
4 ,
No.
3 ,
pp.
$1-18$,

https://doi.org/10.3390/hydrology4030038.

\section{AUTHORS}

Alessandro Massaro (corresponding author): Professor Alessandro Massaro (ING/INF/01, FIS/01,FIS/03) carried out scientific research at the Polytechnic University of Marche, at CNR, and at Italian Institute of Technology (IIT) as Team Leader by activating laboratories for nanocomposite sensors for industrial robotics. He is in MIUR register as scientific expert in competitive Industrial Research and social development, and he is currently head of the Research and Development section and scientific director of MIUR Research Institute Dyrecta Lab Srl. Member of the International Scientific Committee of Measurers IMEKO and IEEE Senior member, recently received an award from the National Council of Engineers as Best Engineer of Italy 2018 (Top Young Engineer 2018). 